\title{
Epidermólise Bolhosa: Foco na Assistência de Enfermagem
}

\author{
Epidermolysis Bullosa: Focus on Nursing Care
}

\author{
Epidermólisis Bullosa: Enfoque en Cuidados de Enfermería
}

Claudia Daniella Avelino Vasconcelos Benício', Nalma Alexandra Rocha de Carvalho', José Diego

Marques Santos ${ }^{1}$, Isabela Ribeiro de Sá Guimarães Nolêto ${ }^{1}$, Maria Helena Barros Araújo Luz

\begin{abstract}
RESUMO
A epidermólise bolhosa é uma doença hereditária ocasionada por mutações em várias proteínas estruturais da pele, representando um quadro clínico grave, cujos defeitos adquiridos ou congênitos da adesão intraepidérmica ou dermoepidérmica levam à formação de bolhas (vesículas) na pele e nas mucosas, podendo ser espontâneas ou provocadas por trauma mínimo. Objetivou-se neste estudo identificar, por meio da literatura científica, temas importantes relacionados à assistência de enfermagem frente ao paciente com epidermólise bolhosa. Tratou-se de uma revisão integrativa de literatura com pesquisa realizada nas bases de dados MEDLINE (via PubMed) e PubMed Central Canada (PMC Canada). Oito artigos científicos compuseram a amostra deste estudo. Foi evidenciado um ambiente sofrível tanto para o paciente como para o enfermeiro durante o tratamento, bem como foram encontradas dificuldades pelo paciente em dispor de curativos e coberturas eficientes para as feridas. O impacto da epidermólise no ambiente psicossocial também foi destacado, com enfoque para o tempo gasto na troca de curativos. Concluiu-se que a enfermagem desempenha um papel relevante no tratamento do paciente com epidermólise bolhosa, haja vista as condições que tal sujeito enfrenta e o potencial do enfermeiro para efetuar cuidados paliativos.
\end{abstract}

DESCRITORES: Estomaterapia. Epidermólise bolhosa. Assistência à saúde. Enfermagem.

\begin{abstract}
Epidermolysis bullosa is an inherited disease caused by mutations in several structural proteins of the skin. It represents a serious medical condition. The acquired or congenital defects of the intra-epidermal or dermal-epidermal adhesion lead to the formation of blisters (vesicles) on the skin and on mucous membranes. In fact, this process may be spontaneous or provoked by minimal trauma. The objective of this study was to identify, using scientific evidence, the major issues related to nursing care towards the patient with epidermolysis bullosa. This study was an integrative literature review that was conducted on MEDLINE (via PubMed) and PubMed Central Canada (PMC Canada). Eight scientific articles were selected to be the sample of this study. A painful environment for both the patient and the nurse during the treatment was evidenced. In addition, some difficulties were seen when the patients were trying to find effective covers and dressings for wounds. In addition, the impact of epidermolysis on the psychosocial environment was also highlighted with emphasis on the time spent on dressing changes. Thus, considering the conditions that the patient faces during the treatment and the potential of nurses to implement a palliative care, nursing professionals play an important role in the treatment of patients with epidermolysis bullosa.
\end{abstract}

DESCRIPTORS: Stomatherapy. Epidermolysis bullosa. Delivery of health care. Nursing.

\footnotetext{
${ }^{1}$ Universidade Federal do Piauí (UFPI) - Teresina (PI), Brasil.

Endereço para correspondência: UFPI, Campus Universitário Ministro Petrônio Portella, Ininga - Departamento de Enfermagem, Bloco SG-12 - CEP:

64049-550 - Teresina (PI), Brasil - E-mail: mhelenal@ufpi.edu.br

Artigo recebido em: 03/12/2014 - Aceito para publicação em: 09/04/2015
} 


\section{RESUMEN}

Epidermólisis ampollosa es una enfermedad hereditaria causada por mutaciones en varias proteínas estructurales de la piel, y representa un cuadro clínico grave, cuyos defectos adquiridos o congénitos de la adhesión intraepidérmica o plomo dérmica resultan en la formación de ampollas (vesículas) en la piel y en las membranas mucosas, las cuales pueden ser espontáneas o provocadas por un trauma mínimo. El objetivo de este estudio fue identificar, a través de la literatura científica, asuntos relacionados con la atención de enfermería hacia el paciente con epidermólisis ampollosa. Se trata de una revisión integradora de la literatura a la investigación realizada en las bases de datos MEDLINE (a través de PubMed) y PubMed Central Canada (PMC Canada). Ocho artículos científicos compusieron la muestra de esto estudio. Se encontró un ambiente tolerable para el paciente y enfermeros durante el tratamiento, así como dificultades por el paciente en tener los curativos y coberturas eficientes para las heridas. El impacto de la epidermólisis en el ambiente psicosocial también se puso de relieve, con un enfoque en el tiempo dedicado a los cambios de curativos. Se concluyó que la enfermería desempeña un papel importante en el tratamiento de pacientes con epidermólisis ampollosa, considerando las condiciones que el paciente enfrenta y el potencial de enfermeros para realizar los cuidados paliativos.

DESCRIPTORES: Estomaterapia. Epidermólisis ampollosa. Prestación de atención de salud. Enfermería.

\section{INTRODUÇÃO}

A Epidermólise Bolhosa (EB) é uma doença hereditária ocasionada por mutações em várias proteínas estruturais da pele, representando um quadro clínico grave, cujos defeitos adquiridos ou congênitos da adesão intraepidérmica ou dermoepidérmica levam à formação de bolhas (vesículas) na pele e nas mucosas, as quais podem ser espontâneas ou provocadas por um trauma mínimo ${ }^{1,2}$.

$\mathrm{O}$ termo EB refere-se às genodermatoses mecanobolhosas, ou seja, aos traumatismos cutâneos de distintas intensidades que podem dar origem às flictenas, cuja gravidade dependerá da mutação envolvida na patogenia. Comumente, manifesta-se na infância, quando os bebês são carregados no colo pelos pais ${ }^{2}$.

Dados atuais mostram que essa patologia afeta cerca de 17.000 nascidos vivos no Reino $U_{n i d o}^{3}$; no entanto, no Brasil, não existem informações publicadas acerca da quantidade de pessoas acometidas por essa doença ${ }^{4}$. Apesar de ser rara, a EB gera um grande impacto na vida do paciente e de sua família, seja em função da dor física, do sofrimento emocional ou do impacto econômico ${ }^{5}$.

A gravidade da EB varia de leve à letal, dependendo de seu subtipo. Muitos dos subtipos mais graves de EB estão associados a complicações, incluindo os extracutâneos como: anemia crônica, osteoporose e problemas gastrintestinais e cardíacos ${ }^{6}$. Em tais casos graves, as lesões esofágicas podem estar presentes, resultando em falta de apetite, náuseas e vômitos crônicos ${ }^{7}$.
Dessa forma, a qualidade de vida desses pacientes é diretamente prejudicada pela patologia, não somente pelos danos físicos, mas também em relação aos bem-estares social e emocional, necessitando assim de uma assistência integrada, individualizada e holística nos serviços de saúde, sobretudo do profissional enfermeiro. Com base no exposto e considerando a magnitude dessa problemática, esse trabalho objetivou identificar, por meio da literatura científica, temas importantes relacionados à assistência de enfermagem frente ao paciente com EB, possibilitando contribuir com informações específicas sobre o tratamento do paciente com EB na prática de enfermagem.

\section{MÉTODOS}

Optou-se pela revisão integrativa da literatura, por tratar-se de um instrumento que tem a capacidade de integrar e generalizar achados, tratamentos e configurações na pesquisa científica. Além do fato de que as revisões de literatura são essenciais para proporcionar o desenvolvimento de profissionais, facilitar a construção de manuais práticos e descobrir, por meio de um conjunto maior de evidências, a razão de considerar muitas estratégias equívocas em várias circunstâncias ${ }^{8}$.

Dessa forma, elaborou-se a seguinte questão norteadora deste estudo: quais são os aspectos de caráter relevante que permeiam a assistência em enfermagem frente à $\mathrm{EB}$ ?

A utilização de tal questão na revisão integrativa possibilita uma síntese do conhecimento já produzido e oferece subsídios 
para a melhoria da assistência à saúde, pois é uma ferramenta essencial no processo de comunicação dos resultados de pesquisa, o que facilita a utilização desses na prática clínica ${ }^{9}$.

A pesquisa foi realizada, em julho de 2014, nas seguintes bases de dados: MEDLINE (via PubMed) e PubMed Central Canada (PMC Canada), utilizando-se os descritores: "nursing" e "epidermolysis bullosa". Como critérios de inclusão adotaram-se: artigo disponível integralmente on-line; escrito no idioma inglês; publicado entre 2005 a 2013; estudo primário ou piloto e que comtemplasse questões relevantes sobre a EB no contexto profissional da prática de enfermagem (eixo temático). Excluíram-se: artigos não disponibilizados na íntegra e/ou fora do eixo temático; relatos de caso; editoriais e reflexões.

A coleta de dados baseou-se no instrumento validado por Ursi (2005), no qual foram utilizados os seguintes itens de caracterização: título, objetivo, amostra, principais achados dos estudos, autores e periódico, os quais serviram de alicerce para o desenvolvimento do Quadro $1^{10}$.

$\mathrm{Na}$ base de dados MEDLINE (via PubMed), limitou-se a pesquisa para "estudos disponíveis integralmente on-line" e, a partir da busca com descritores específicos, encontraram-se 43 artigos científicos. Entretanto, desses, apenas seis foram selecionados para a amostra desta revisão após a aplicação dos critérios de inclusão e exclusão. Já na base de dados PubMed Central Canada (PMC Canada), partindo-se dos descritores e uso do critério de inclusão, ou seja, artigos disponíveis na íntegra, encontraram-se sete textos completos. A seguir, aplicando-se os critérios de inclusão e exclusão, restaram dois artigos. Em suma, oito artigos compuseram a amostra final desta revisão integrativa.

A análise das referências foi feita por meio da leitura reiterada dos oito artigos selecionados e de sua sistematização específica, demonstrada no Quadro 1, que é composto por colunas referentes à caracterização dos artigos (título, objetivo, amostra, principais achados dos estudos, autores e periódico), para facilitar a visualização dos achados, bem como a elaboração dos resultados e das discussões.

Para a escrita deste estudo, seguiram-se as dez regras de Pautasso ${ }^{11}$, que dão orientações sobre como escrever uma revisão de literatura, a saber: definição de tópico e audiência (EB/profissionais de enfermagem), levantamento no banco de dados, anotações e comentários durante a leitura dos artigos, delimitação do tipo de revisão (integrativa), manutenção do foco na temática, uso do pensamento crítico e consistente, busca pela estrutura lógica, troca de ideias e discussão entre os autores sobre os resultados, objetivação da escrita e busca de citações atualizadas ${ }^{11}$.

Quadro 1. Títulos, objetivos, amostras, principais achados dos estudos, autores e periódicos dos artigos incluídos nesta revisão de literatura.

\begin{tabular}{|c|c|c|c|c|c|}
\hline Título & Objetivo & Amostra & $\begin{array}{c}\text { Principais } \\
\text { achados do estudo }\end{array}$ & Autor(es) & Periódico \\
\hline $\begin{array}{l}\text { Living in dressings } \\
\text { and bandages: } \\
\text { findings from } \\
\text { workshops with } \\
\text { people with } \\
\text { Epidermolysis } \\
\text { bullosa }\end{array}$ & $\begin{array}{l}\text { Descrever os } \\
\text { resultados } \\
\text { das oficinas } \\
\text { com adultos } \\
\text { diagnosticados } \\
\text { com EB, } \\
\text { juntamente com } \\
\text { as observações } \\
\text { das trocas de } \\
\text { curativos. }\end{array}$ & $\begin{array}{l}\text { Participantes com } \\
\text { feridas extensas e } \\
\text { necessidades não } \\
\text { satisfeitas com } \\
\text { curativos } \\
\text { convencionais. } \\
\text { Cuidadores e } \\
\text { enfermeiros } \\
\text { especializados em } \\
\text { EB também foram } \\
\text { incluídos. Ao todo, } \\
\text { participaram } 20 \\
\text { sujeitos. }\end{array}$ & $\begin{array}{l}\text { Um significante } \\
\text { número de limitações } \\
\text { foi encontrado em } \\
\text { relação à utilização de } \\
\text { coberturas. Aquelas } \\
\text { que deveriam ser } \\
\text { utilizadas para cobrir } \\
\text { apenas uma ferida } \\
\text { eram usadas para } \\
\text { cobrir feridas extensas } \\
\text { e múltiplas. }\end{array}$ & $\begin{array}{l}\text { Grocott } \\
\text { et al. }{ }^{12}\end{array}$ & $\begin{array}{l}\text { International } \\
\text { Wound } \\
\text { Journal }\end{array}$ \\
\hline $\begin{array}{l}\text { Topical diacerein } \\
\text { for epidermolysis } \\
\text { bullosa: a } \\
\text { randomized } \\
\text { controlled pilot } \\
\text { study }\end{array}$ & $\begin{array}{l}\text { Testar a hipótese } \\
\text { de que uma } \\
\text { aplicação tópica } \\
\text { de diacereína } \\
(1 \%) \text { reduz a } \\
\text { formação de } \\
\text { bolhas. }\end{array}$ & $\begin{array}{l}\text { Cinco pacientes } \\
\text { que receberam } \\
\text { ambos: placebo e } \\
\text { intervenção. }\end{array}$ & $\begin{array}{l}\text { A aplicação de } \\
\text { diacereîna (1\%) } \\
\text { pode diminuir } \\
\text { significativamente a } \\
\text { formação de bolhas } \\
\text { em até duas semanas. }\end{array}$ & $\begin{array}{l}\text { Wally } \\
\text { et al.13 }\end{array}$ & $\begin{array}{l}\text { Orphanet } \\
\text { Journal } \\
\text { of Rare } \\
\text { Diseases }\end{array}$ \\
\hline
\end{tabular}


Quadro 1. Continuação.

\begin{tabular}{|c|c|c|c|c|c|}
\hline Título & Objetivo & Amostra & $\begin{array}{c}\text { Principais } \\
\text { achados do estudo }\end{array}$ & Autor(es) & Periódico \\
\hline $\begin{array}{l}\text { A consensus } \\
\text { approach to wound } \\
\text { care in epidermolysis } \\
\text { bullosa }\end{array}$ & $\begin{array}{l}\text { Elaboração de } \\
\text { uma lista de } \\
\text { recomendações } \\
\text { para melhor } \\
\text { embasar os } \\
\text { profissionais } \\
\text { que cuidam de } \\
\text { pacientes com EB. }\end{array}$ & $\begin{array}{l}\text { Quinze } \\
\text { profissionais de } \\
\text { saúde em geral. }\end{array}$ & $\begin{array}{l}\text { Recomendações } \\
\text { específicas para o } \\
\text { tratamento da EB } \\
\text { poderão fornecer } \\
\text { aos profissionais uma } \\
\text { orientação de como } \\
\text { cuidar dos pacientes } \\
\text { com EB. }\end{array}$ & $\begin{array}{l}\text { Pope } \\
\text { et al. }{ }^{14}\end{array}$ & $\begin{array}{l}\text { Journal } \\
\text { of the } \\
\text { American } \\
\text { Academy of } \\
\text { Dermatology }\end{array}$ \\
\hline $\begin{array}{l}\text { The psychosocial } \\
\text { impact of chronic } \\
\text { wounds on } \\
\text { patients with severe } \\
\text { epidermolysis bullosa }\end{array}$ & $\begin{array}{l}\text { Explorar a } \\
\text { experiência vivida } \\
\text { de indivíduos com } \\
\text { feridas crônicas } \\
\text { associadas à } \\
\text { epidermólise } \\
\text { bolhosa distrófica } \\
\text { e juncional. }\end{array}$ & $\begin{array}{l}\text { Seis pacientes } \\
\text { com epidermólise } \\
\text { bolhosa distrófica } \\
\text { ou juncional. }\end{array}$ & $\begin{array}{l}\text { Pacientes com EB } \\
\text { carecem de uma } \\
\text { atenção multidisciplinar } \\
\text { que não se limite } \\
\text { apenas ao controle da } \\
\text { dor, mas que abranja os } \\
\text { aspectos psicossociais } \\
\text { dos pacientes. }\end{array}$ & $\begin{array}{l}\text { Adni, } \\
\text { Martin e } \\
\text { Mudge }^{15}\end{array}$ & $\begin{array}{l}\text { Journal of } \\
\text { Wound Care }\end{array}$ \\
\hline $\begin{array}{l}\text { Co-producing } \\
\text { novel wound } \\
\text { care products } \\
\text { for epidermolysis } \\
\text { bullosa; an empirical } \\
\text { case study of the } \\
\text { use of surrogates } \\
\text { in the design } \\
\text { and prototype } \\
\text { development process }\end{array}$ & $\begin{array}{l}\text { Identificar, por } \\
\text { meio de oficinas, } \\
\text { problemas com } \\
\text { a utilização dos } \\
\text { curativos atuais } \\
\text { e produtos } \\
\text { para feridas de } \\
\text { pacientes } \\
\text { com EB. }\end{array}$ & $\begin{array}{l}\text { Grupos com até } \\
20 \text { pacientes } \\
\text { com EB e seus } \\
\text { cuidadores, } \\
\text { juntamente } \\
\text { com até oito } \\
\text { enfermeiros } \\
\text { especialistas } \\
\text { em EB. }\end{array}$ & $\begin{array}{l}\text { Há limitações nos } \\
\text { curativos atuais para } \\
\text { as feridas oriundas } \\
\text { da EB, especialmente } \\
\text { quando se trata } \\
\text { de tamanho, } \\
\text { estabilidade, conforto, } \\
\text { temperatura e } \\
\text { controle de exsudato. }\end{array}$ & $\begin{array}{l}\text { Grocott } \\
\text { et al. }{ }^{16}\end{array}$ & $\begin{array}{l}\text { International } \\
\text { Wound } \\
\text { Journal }\end{array}$ \\
\hline $\begin{array}{l}\text { You're whatever the } \\
\text { patient needs at the } \\
\text { time': the impact on } \\
\text { health and social } \\
\text { care professionals of } \\
\text { supporting people } \\
\text { with epidermolysis } \\
\text { bullosa }\end{array}$ & $\begin{array}{l}\text { Investigar } \\
\text { o impacto } \\
\text { emocional } \\
\text { sofrido pelos } \\
\text { profissionais } \\
\text { que assistem } \\
\text { pacientes } \\
\text { com EB. }\end{array}$ & $\begin{array}{l}\text { Enfermeiros, } \\
\text { assistentes } \\
\text { sociais e demais } \\
\text { profissionais } \\
\text { de saúde } \\
\text { especialistas em } \\
\text { EB, com o total de } \\
33 \text { participantes. }\end{array}$ & $\begin{array}{l}\text { O bem-estar de } \\
\text { profissionais de } \\
\text { saúde que lidam } \\
\text { com pacientes com } \\
\text { EB pode ser afetado } \\
\text { negativamente devido à } \\
\text { carência de profissionais } \\
\text { especialistas em EB; e } \\
\text { a preocupação com } \\
\text { o estado de saúde do } \\
\text { paciente. }\end{array}$ & $\begin{array}{l}\text { Dures } \\
\text { et al. }{ }^{17}\end{array}$ & \\
\hline $\begin{array}{l}\text { Development of allele- } \\
\text { specific therapeutic } \\
\text { siRNA for keratin } \\
5 \text { mutations in } \\
\text { epidermolysis bullosa } \\
\text { simplex }\end{array}$ & $\begin{array}{l}\text { Descrever o } \\
\text { desenvolvimento } \\
\text { de alelos } \\
\text { terapêuticos para } \\
\text { mutações na EB. }\end{array}$ & $\begin{array}{l}\text { Testes } \\
\text { laboratoriais com } \\
\text { proteínas. }\end{array}$ & $\begin{array}{l}\text { O RNA interference pode } \\
\text { atuar seletivamente, } \\
\text { silenciando alelo } \\
\text { mutante, que é um dos } \\
\text { fatores responsáveis } \\
\text { pelas feridas. }\end{array}$ & $\begin{array}{l}\text { Atkinson } \\
\text { et al. }{ }^{18}\end{array}$ & $\begin{array}{l}\text { Journal of } \\
\text { Investigative } \\
\text { Dermatology }\end{array}$ \\
\hline $\begin{array}{l}\text { Impact of inherited } \\
\text { epidermolysis } \\
\text { bullosa on parental } \\
\text { interpersonal } \\
\text { relationship, } \\
\text { marital status and } \\
\text { family size }\end{array}$ & $\begin{array}{l}\text { Avaliar o impacto } \\
\text { da presença de } \\
\text { EB em crianças } \\
\text { sobre } \\
\text { as relações } \\
\text { conjugais de } \\
\text { seus pais. }\end{array}$ & $\begin{array}{l}374 \text { pacientes com } \\
\text { EB ( } 234 \text { adultos e } \\
140 \text { crianças com } \\
\text { idade inferior a } 18 \\
\text { anos). }\end{array}$ & $\begin{array}{l}\text { A presença de uma } \\
\text { criança com EB pode } \\
\text { afetar negativamente } \\
\text { a sua família. Isso } \\
\text { ocorre em função } \\
\text { da necessidade de } \\
\text { cuidados intensivos com } \\
\text { as feridas da criança. }\end{array}$ & $\begin{array}{l}\text { Fine } \\
\text { et al. }{ }^{19}\end{array}$ & $\begin{array}{l}\text { British } \\
\text { Journal of } \\
\text { Dermatology }\end{array}$ \\
\hline
\end{tabular}




\section{RESULTADOS E DISCUSSÃO}

De acordo com o delineamento da pesquisa, observou-se que os estudos são de periódicos internacionais específicos na abordagem de dermatologia, doenças crônicas, feridas e doenças raras. Percebeu-se, também, uma escassez de pesquisas primárias e/ou pilotos que retratassem aspectos da enfermagem frente à $\mathrm{EB}$.

A respeito do local das pesquisas, o Reino Unido abarcou cinco dos estudos (62,5\%), seguido do Canadá (12,5\%), dos Estados Unidos (12,5\%) e da Áustria (12,5\%). Apesar da EB ser um tema que necessita de estudos, nota-se que, em países mais desenvolvidos, essa doença crônica recebe mais investimento na investigação científica, como pode-se observar no Quadro 1.

Os resultados foram categorizados conforme o eixo temático evidenciado em cada um dos artigos. Dessa forma, a discussão foi pautada em três categorias, a saber: desafios no cuidado ao paciente com EB; estratégias utilizadas por profissionais de saúde no tratamento das feridas de pacientes com EB e impacto psicossocial ao paciente com EB. As categorias foram formadas levando-se em conta os principais achados das referências analisadas, os quais obedeceram aos objetivos, como observado no Quadro 1.

O primeiro estudo ${ }^{12}$ teve, como seu principal achado, limitações em relação à utilização de coberturas. Aquelas que deveriam ser utilizadas para cobrir apenas uma ferida eram usadas para cobrir feridas extensas e múltiplas. Já o segundo ${ }^{13}$ obteve que a aplicação de diacereína (1\%) pode diminuir significativamente a formação de bolhas em até duas semanas; enquanto que, no terceiro ${ }^{14}$, encontraram-se recomendações específicas para o tratamento da $\mathrm{EB}$, as quais poderão fornecer aos profissionais uma orientação de como cuidar de pacientes com EB. Na quarta ${ }^{15}$ investigação, identificou-se que pacientes com $\mathrm{EB}$ carecem de uma atenção multidisciplinar que não se limite apenas ao controle da dor, mas que abranja os aspectos psicossociais dos pacientes.

No quinto estudo ${ }^{16}$, observou-se que há limitações nos curativos atuais para feridas oriundas da EB, especialmente quando se trata de tamanho, estabilidade, conforto, temperatura e controle de exsudato; já no sexto ${ }^{17}$, os resultados mostraram que o bem-estar dos profissionais de saúde que lidam com pacientes com EB pode ser afetado negativamente, em função da carência de profissionais especialistas em EB e da preocupação com o estado de saúde do paciente.
O sétimo ${ }^{18}$ identificou que o RNA interference pode atuar seletivamente silenciando o alelo mutante, que é um dos fatores responsáveis pelas feridas. Enquanto que, no oitavo estudo $^{19}$, destacou-se que a presença de uma criança com EB pode afetar negativamente a sua família.

Com relação à amostra dos estudos, $25 \%$ das referências analisadas tiveram como participantes, tanto os pacientes como os cuidadores e profissionais de saúde. Já outros $25 \%$ tiveram como amostra os profissionais de saúde; $37 \%$ dos estudos tiveram como participantes somente pacientes; e $13 \%$, que corresponde a apenas um estudo, tiveram como amostra testes laboratoriais com proteínas.

\section{Desafios no cuidado ao paciente com epidermólise bolhosa}

A principal característica da EB é o surgimento de feridas crônicas na pele que geralmente são pequenas, numerosas, dolorosas, desconfortáveis e com grande quantidade de exsudato. Tais sintomas foram citados como infortúnios no cotidiano dos pacientes que vivenciam esta condição ${ }^{12,15,16}$.

Dessa forma, o cuidado das feridas é a base do tratamento para pacientes com EB. No entanto, atualmente, não há diretrizes específicas que contribuam para o cuidado dos profissionais com esses pacientes ${ }^{14}$. Os profissionais que trabalham diretamente com esse público afirmam a necessidade de um trabalho mais planejado e organizado, pois assim facilitar-se-á a qualidade do cuidado na tomada de decisões ${ }^{17}$.

Além disso, identificou-se a dificuldade que tais profissionais têm em se desvincular afetivamente dos pacientes, uma vez que se sentem aflitos e tristes com a situação deles. Percebeu-se que os enfermeiros, geralmente, são empáticos diante dos pacientes, reconhecendo e compreendendo o sofrimento vivenciado por estes, bem como pelos cuidadores. Essa situação afeta a qualidade de vida do profissional e dificulta o equilíbrio entre trabalho e vida social. Consequentemente, isso interfere na forma do cuidado ${ }^{17}$.

Ressalta-se ainda o fato de os enfermeiros generalistas apresentarem dificuldades em tratar um paciente com EB, pois se sentem despreparados frente às necessidades que a patologia exige ${ }^{12,16}$. Com isso, os pacientes relataram não sentir confiança nos profissionais que não eram especialistas em $\mathrm{EB}^{15} \mathrm{e}$, muitas vezes, relutaram receber assistência dos mesmos ${ }^{17}$. Essa situação pode ser considerada um problema, 
tendo em vista que os profissionais especialistas são escassos e os pacientes com EB necessitam de cuidados contínuos.

A raridade da doença gera uma carga de ansiedade aos profissionais, resultando em uma situação de incapacidade frente às atividades de assistência em enfermagem. Assim, os enfermeiros têm dificuldade em realizar o cuidado, por este ser muitas vezes extensivo, complicado e não gerar tantos resultados positivos em função da $\mathrm{EB}$ ser incurável. Esta realidade provoca um sentimento de incompetência, frustração e culpa, devido à impressão de que a assistência não está possibilitando benefícios, nem sendo impactante ou significativa na vida dos pacientes ${ }^{17}$.

Os enfermeiros que lidam diretamente com os pacientes com EB perceberam o quão multifacetada é a assistência, pois requer cuidados médicos, psicossociais e práticos ${ }^{17}$. Por isso, a equipe deve trabalhar de forma harmoniosa e integrada para, então, obter êxito no tratamento.

Uma pesquisa, que elaborou planos de abordagem ao paciente com EB por meio de entrevistas com a equipe multiprofissional, identificou que, para o cuidado adequado aos pacientes, é indispensável o desenvolvimento de uma terapia de relacionamento. Esta deve envolver apoio e educação apropriada, pois havendo confiança, comunicação e diálogo aberto, permite-se que os pacientes e seus cuidadores entendam que cada pessoa que o assiste tem uma contribuição significativa em seu processo de recuperação ${ }^{14}$.

\section{Estratégias utilizadas por profissionais de saúde no tratamento das feridas de pacientes com epidermólise bolhosa}

A EB traz consigo modificações que afetam vários sistemas do corpo humano, em especial a epiderme, ocorrendo formações constantes de bolhas, feridas, dor e desconforto na pele. Os pacientes com essa patologia consideram-se “pessoas borboletas”, em função da fragilidade da pele ${ }^{12,16}$. Para os cuidados contra isso, ressalta-se a promoção da independência e segurança do paciente nas atividades diárias, requerendo modificações no ambiente, tais como o uso de camas especiais, assentos em banheiras, cadeiras de rodas, calçados, entre outros ${ }^{14}$.

As feridas crônicas da EB são consideradas pelos pacientes como inerentes a eles, já que tentam aceitar a condição de saúde e até mesmo se esforçam para ter uma vida normal, apesar das dificuldades que a doença os impõe. Apesar de tentarem se adaptar aceitando a doença, por vezes os pacientes sentem-se frustrados quando ocorre infecção nas feridas, perda de controle do exsudado ou aumento exagerado no número de feridas ${ }^{15}$.

O tratamento de tais lesões na população com EB apresenta diversos desafios, entre eles a variabilidade clínica para um plano de gestão individualizada, pois a disponibilidade de vários produtos para o tratamento das feridas dificulta o processo de decisão, além do grande custo dessas coberturas para o orçamento da família e para as unidades de saúde ${ }^{12,15,16}$. Portanto, a avaliação precoce da ferida e o manejo adequado de tratamento são os pilares do cuidado a esses pacientes.

A prioridade para pacientes com EB é prevenir a lesão cutânea, já que essa patologia é muito problemática devido à fragilidade da pele. Vestir roupas casuais, por exemplo, podem eventualmente causar a formação de bolhas e levar à formação de feridas ${ }^{12}$.

Por isso, antes de decidir sobre uma estratégia para a gestão dos cuidados de feridas, é importante fazer uma investigação da área de superfície do corpo afetada à procura dos tipos de comprometimento da pele (bolhas intactas, erosões e feridas crônicas). Entretanto, a maioria dos pacientes são muito relutantes em expor sua superfície inteira da pele em cada visita. Muitas vezes, a equipe de cuidado deve negociar um cronograma do exame da pele rotativo, o qual permita que toda a superfície da pele seja cuidadosamente inspecionada pelo menos a cada seis meses. Os sinais de infecção local, como o aumento da vermelhidão, a dor local, o odor e o exsudato, devem ser documentados em cada ferida ${ }^{14}$.

Infelizmente, ainda há uma quantidade significante de limitações que foram encontradas em produtos designados para o tratamento de feridas. Em geral, as coberturas atuais não suprem as necessidades de pessoas com EB, interferindo diretamente na eficácia do tratamento e necessitando, portanto, de pesquisas para o desenvolvimento de produtos mais eficazes ${ }^{12,16}$.

Apesar da escassez de produtos direcionados exclusivamente para feridas da EB, estudos mostram algumas substâncias que podem fornecer grandes resultados e melhorar a qualidade de vida desses pacientes. Testou-se, na Áustria, uma substância chamada 'diacereína', a qual trouxe como aspecto positivo a redução significativa de bolhas em duas semanas de uso. Além disso, seu efeito benéfico demonstrou ser ainda mais estável e perdurar por várias semanas após a cessação do uso tópico ${ }^{13}$. 
Além dessa substância, há pesquisas que mostram avanços no tratamento das lesões de pele da EB, trata-se do RNA interference, o qual se mostrou promissor no tratamento por atuar seletivamente silenciando alelo mutante, que é um dos fatores responsáveis pelas feridas ${ }^{18}$.

Porém, a realidade atual ainda é preocupante. $\mathrm{O}$ uso de produtos no tratamento de feridas na EB tem apresentado problemas como: risco de infecção, formação de exsudato, odor fétido, e não eficácia na prevenção de futuras feridas na pele delicada ${ }^{12,16}$. Os curativos, criados para cobrir uma só ferida, geralmente são usados para ocluir grande extensão do corpo com essas lesões. Além disso, os métodos ideais de avaliação seriada das feridas em pacientes com EB ainda são escassos ${ }^{14}$.

Por falta de variedade e do acesso de coberturas específicas para as feridas, os portadores de EB afirmaram que adaptam e combinam coberturas de forma improvisada, utilizando o que há disponível atualmente. Entretanto, as coberturas se mostram ineficientes em controlar o exsudato e parecem não se adaptarem aos contornos no corpo. Além destes problemas, percebeu-se que, durante os movimentos corporais, as coberturas se aproximam e compactam a pele ${ }^{12,16}$.

Ainda quanto às feridas da $\mathrm{EB}$, um fato importante a ser mencionado é a relevância da avaliação dessas lesões na detecção dos tumores neoplásicos. Essa avaliação é realizada, na maioria das vezes, pela equipe de enfermagem durante a troca dos curativos e pelo exame da pele afetada ${ }^{15}$. Salienta-se que, durante a avaliação, pode-se perceber modificações das características da pele e das lesões, tais como o aparecimento ou o crescimento de saliências, que devem ser comunicadas ao profissional médico para o esclarecimento do diagnóstico.

A dor também é um relato bem prevalente entre os portadores de EB.É o sintoma comum experimentado por pacientes com esta doença, independentemente do subtipo, embora a sua causa nesta patologia seja multifatorial, a pele e as lesões relacionadas à ela são, de longe, a fonte mais significativa de dor ${ }^{14}$.

Pacientes do estudo de Adni, Martin e Mudge relataram sentir muita dor, comprometendo a sua qualidade de vida. Apesar de restringirem-se às atividades rotineiras diárias, os sujeitos tentavam ser resilientes à dor e não depender de analgésicos ${ }^{15}$. Essa restrição à analgesia é explicada em outro estudo, o qual afirma que tal fato ocorre devido ao receio dos participantes em relação aos efeitos colaterais, tais como a sonolência que afeta diretamente a sua vida ativa ${ }^{12}$.
Embora os avanços sejam perceptíveis, outros resultados relacionados à ferida, como redução da dor, diminuição da carga bacteriana e exsudato, parecem ser os mais atingíveis. A abordagem centralizada multiprofissional com a coordenação dos cuidados, incluindo a comunicação aberta com a equipe hospitalar e de assistência domiciliar, é a maneira mais eficaz de cuidar desses pacientes ${ }^{14}$.

\section{Impacto psicossocial à família e ao paciente com epidermólise bolhosa}

Por ser uma patologia rara que afeta a pele do paciente, a EB é uma doença muito desconfortável não só fisiologicamente, mas socialmente. O nascimento de uma criança com EB é um evento traumático para uma família, necessitando de apoio individualizado. Nesse momento, é importante uma contribuição conjunta por parte dos profissionais experientes, enfatizando a importância da união familiar para possibilitar a oferta do melhor atendimento ao seu bebêt ${ }^{14}$.

Os pais de crianças com EB admitiram serem afetados negativamente em suas vidas pessoais e de relacionamento como um casal. Devido aos cuidados prolongados, eles acabam sendo consumidos física e mentalmente, diminuindo seus interesses, tempo e oportunidade para interagir em atividades que não estivessem relacionadas aos cuidados diários às feridas das crianças ${ }^{19}$.

Essa patologia provoca um impacto negativo relevante na vida diária dos pacientes, os quais apresentam uma deficiência de autoconfiança e autoestima que pode se manifestar em uma variedade de formas: medo, depressão, ansiedade, frustração e ira ${ }^{12,15,16}$.

A doença interfere totalmente na rotina dos pacientes em função, principalmente, às feridas na pele. Como estas lesões podem afetar todo o corpo do paciente, elas demandam um grande tempo de aplicação das coberturas, o que limita os pacientes de realizarem atividades sociais. Além disso, as vestimentas também impacientam e incomodam os pacientes por entrarem em contato direto com a pele lesionada. Desta forma, devem ser usadas roupas que ofereçam proteção e conforto para as feridas, tentando adequá-las à personalidade e ao estilo do paciente ${ }^{12,15}$.

Assim, a presença de uma rede de apoio, como amigos, família e profissionais, que ajude o paciente a lidar com o medo, a ansiedade e a depressão, proporciona uma melhor qualidade de vida ao paciente ${ }^{12,15-17,19}$. 


\section{CONCLUSÃO}

A EB é uma doença rara, mas, quando ocorre, compromete o paciente e pode não apenas provocar péssimos níveis de bem-estar, como também prejudicar consideravelmente a qualidade de vida. Observou-se que a dor, o receio quanto ao uso de analgésicos e de utilizar produtos para o cuidado paliativo que tragam resultados significativos, o isolamento social por conta do tempo gasto em curativos e pela não aceitação da autoimagem e a limitação de profissionais especialistas na área, juntos, promovem um ambiente de aflição ao paciente carente de assistência adequada.

Considerando que pacientes com EB, atualmente, ainda não possuem expectativa de cura, a implementação dos cuidados de enfermagem fundamentados em evidências é essencial para promover um melhor estado de saúde aos pacientes, favorecendo melhorias na qualidade de vida não somente do paciente como também do cuidador.

Conclui-se que a enfermagem necessita aprimorar suas práticas para assistir ao paciente com EB. Para isso, é necessário que se encoraje cada vez mais o desenvolvimento de futuras pesquisas que avaliem quais são os melhores curativos e/ou coberturas que auxiliem o paciente. Deve-se desenvolver também treinamento para profissionais generalistas sobre especificidades da EB, bem como para avaliar a dor e os demais cuidados paliativos que podem ser prestados aos pacientes que vivenciam esta condição, pois somente é possível prestar um cuidado de qualidade quando se tem conhecimento acerca de todas as questões que envolvem tanto a doença como o paciente, em seus aspectos físico, social e psicológico.

\section{REFERÊNCIAS}

1. Marinkovich MP, Bauer EA. Inherited Epidermolysis Bullosa. In: Wolff K, Goldsmith L, Katz S, Gilchrest B, Paller A, Leffel D. Fitzpatrick's Dermatology in General Medicine. 7. ed. USA: McGraw-Hill Professional; 2008.

2. Braga-Silva J, Gerhardt S. Epidermólise bolhosa distrófica: aspectos dermatológicos e cirúrgicos. Revista AMRIGS. 2014;58(1):65-8

3. DEBRA Home [Internet]. A sociedade Portuguesa de Epidermólise bolhosa. [cited 2014 Jul 22]. Available from: https://www.debra.org.uk

4. Prazeres SJ. Tratamento de feridas: teória e prática. Porto Alegre: Moriá Editora; 2009.

5. Margari F, Lecce $P$, Santamato $W$, Ventura $P$, Sportelli $N$, Annicchiarico $G$, et al. Psychiatric symptoms and quality of life in patients affected by epidermolysis bullosa. J Clin Psychol Med Settings. 2010;17(4):333-9.

6. Cuesta C, Blow T, Tranter S. Epidermolysis bullosa: a rare challenge for peritoneal dialysis nurses. Renal Soc Australasia J. 2013;9(1):41-4

7. Denyer J. Wound management for children with epidermolysis bullosa. Dermatol Clin. 2010;28(2):257-64.

8. Rhoades E. [Commentary on] Literature Reviews. Volta Review. 2011;111(3):353-68.

9. Mendes KD, Silveira RC, Galvão CM. Revisão integrativa: método de pesquisa para a incorporação de evidências na saúde e na enfermagem. Texto Contexto Enferm. 2008;17(4):758-64.

10. Ursi ES. Prevenção de lesões de pele no perioperatório: revisão integrativa da literatura. [dissertação]. Ribeirão Preto: Universidade de São Paulo, Escola de Enfermagem de Ribeirão Preto; 2005.

11. Pautasso M. Ten Simple Rules for Writing a Literature Review. PLoS Computational Biology [serial on the Internet]. 2013;9(7):1-4. Cited 2014 Jul 22]. [cited 2014 Jul 22].
Available from: http://www.ncbi.nlm.nih.gov/pmc/articles/ PMC3715443/?report=reader

12. Grocott $\mathrm{P}$, Blackwell R, Weir H, Pillay E. Living in dressings and bandages: findings from workshops with people with Epidermolysis bullosa. Int Wound J. 2013;10(3):274-84.

13. Wally V, Kitzmueller S, Lagler F, Moder A, Hitzl W, Wolkersdorfer $\mathrm{M}$, et al. Topical diacerein for epidermolysis bullosa: a randomized controlled pilot study. Orphanet J Rare Dis. 2013;8(1):69:1-3.

14. Pope E, Lara-Corrales I, Mellerio J, Martinez A, Schultz G, Burrell R, et al. A consensus approach to wound care in epidermolysis bullosa. J Am Academy Dermatol. 2012;67(5):904-17

15. Adni T, Martin K, Mudge E. The psychosocial impact of chronic wounds on patients with severe epidermolysis bullosa. J Wound Care. 2012;21(11):528-38.

16. Grocott P, Blackwell R, Currie C, Pillay E, Robert G. Coproducing novel wound care products for Epidermolysis bullosa; an empirical case study of the use of surrogates in the design and prototype development process. Int Wound J. 2013;10(3):265-73

17. Dures E, Morris M, Gleeson K, Rumsey N. 'You're whatever the patient needs at the time': the impact on health and social care professionals of supporting people with epidermolysis bullosa. Chron Illness. 2010;6(3):215-27.

18. Atkinson S, McGilligan V, Liao H, Szeverenyi I, Smith F, Moore $C$, et al. Development of allele-specific therapeutic siRNA for keratin 5 mutations in epidermolysis bullosa simplex. J Investigative Dermatol. 2011;131(10):2079-86.

19. Fine J, Johnson $L$, Weiner $M$, Suchindran $C$. Impact of inherited epidermolysis bullosa on parental interpersonal relationships, marital status and family size. Brit J Dermatol. 2005;152(5):1009-14. 